\title{
Distal femur fractures in adults
}

\section{Abstract}

Keywords: femoral fractures, femur, surgery, leg injuries

\section{Introduction}

Distal femur fractures are a relatively uncommon fracture, but an important cause of patient morbidity ${ }^{1}$. Surgical management can be technically challenging ${ }^{2}$, with no clear advantage of any one particular surgical implant ${ }^{3}$. Despite increased biomechanical and clinical research and the development of modern implants, persistent disability and poor clinical outcome often results ${ }^{4}$. Some of the poorer outcomes may relate to surgical technique and a lack of understanding of the principles applied to management of these fractures.

\section{Epidemiology}

Distal femoral fractures account for $4-6 \%$ of all femoral fractures ${ }^{5}$ and approximately one third of all femoral shaft fractures ${ }^{6}$. They have a bimodal age distribution, tending to occur in either young males, from high energy trauma or elderly females with osteoporosis sustained from low energy trauma ${ }^{1,7,8}$. 85\% of low energy fractures occur in the elderly population ${ }^{7}$ In low energy trauma, most fractures remain extra-articular ${ }^{7}$, whereas in high energy trauma over half have intra-articular extension ${ }^{4}$. Extra-articular and intra-articular comminution is frequent ${ }^{4,9}$. Open fractures occur in $19 \%-54 \%{ }^{10}$, with up to $80 \%$ being Gustilo type III ${ }^{4}$. Approximately 1-5\% of primary knee arthroplasties ${ }^{11-14}$ are complicated by peri-prosthetic fracture.

\section{Anatomy and blood supply}

The femur is a tubular bone with an anterior bow and a flare at the distal femoral condyles. The femoral shaft is oriented at $7^{\circ}$ of valgus in relation to the knee joint ${ }^{15}$. The distal end of the femur is a trapezoid in cross section, described by the lateral and medial condyles, the articular margin of the trochlear and intercondylar notch (Figure 1 and Figure 2). The femoral diaphysis receives blood supply from nutrient arteries, branches of the profunda femoris artery, which supply the inner two thirds of the cortex. The outer one third receives blood from periosteal vessels derived from the soft tissue.

\section{Fracture classification}

Fractures of the distal femur are most commonly classified using the AO/OTA Fracture Classification (Table 1, Figure 3). Type C fractures are the most common. They can be further divided into three groups, and then sub-groups, according to the degree of articular and metaphyseal comminution (Figure 4).

Periprosthetic fractures have been classified according to the Lewis and Rorabeck classification (Table 2) ${ }^{16}$. Fractures in this population are related to bone quality, typically being osteoporotic in nature, complicated by stress shielding by the implant, distal femoral notching, arthrofibrosis and loosening of implants ${ }^{17}$. 


\section{Assessment and initial management}

\section{Initial Management}

In the high energy trauma patient, initial assessment and management should be guided by Advanced Trauma Life Support principles ${ }^{18}$. For both low and high energy fractures, initial management includes traction or splinting. Hypotension and haemodynamic instability should be assessed and managed, with other potential sites of blood loss excluded. The patient's physiological status should be assessed to determine whether damage control orthopaedics or early total care is most appropriate. Assessment of the knee is difficult with a fracture present, and an examination under anaesthesia of the knee after fracture fixation is recommended in every operative case to assess for ligamentous injury.

\section{History}

History should include mechanism and preceding pain or other symptoms to exclude a pathological nature to the fracture. If a total knee or hip arthroplasty is in situ, a history of function including symptoms suggestive of aseptic or septic loosening or instability is required. A loose prosthesis may require revision arthroplasty with a plan for concurrent fixation or excision of the fracture. Implant details need to be determined as this may alter management options and timing.

\section{Examination}

Assessment of neurovascular status should occur in every case. Open fractures and other ipsilateral limb and other injury should be assessed as this too may influence surgical management, timing and implant choice.

\section{$\underline{\text { Imaging }}$}

Standard radiographic imaging with two views of the fracture site should occur. Full length femur x-rays should be included which will exclude other fractures in the femur and the presence of implants. In high energy fractures, a CT scan of the pelvis often occurs and fine cuts of the femoral neck should be carefully perused for femoral neck fracture. If the intra-articular component is complex, CT scan of the knee is helpful for surgical planning.

\section{Non-operative management}

Distal femur fractures are unstable injuries. In an elderly patient it is desirable to achieve full weight bearing to enable early mobility, and surgical management with modern implants have allowed for this ${ }^{19,20}$. A small randomised controlled trial involving elderly patients indicates that surgical treatments are likely to be superior to non-operative management ${ }^{21}$. It is rare that non-operative treatment is offered. Non-operative management is reserved for the medically unfit or nonambulatory patients with poor bone stock.

\section{Operative management}

Options for surgical interventions include antegrade or retrograde intramedullary nailing, open indirect or direct reduction and fixation with fixed angle locking plates or traditional plating, external fixation and arthroplasty ${ }^{3}$. Implant choice can be based on fracture type (Table 3).The most common surgical methods employed in modern practice are retrograde nailing or 
angular-stable anatomical locking plate osteosynthesis, with locking plate osteosynthesis the most commonly used method ${ }^{1,22}$. It is unclear how much benefit the addition of locked compared with non-locked plates has made 23,24 . In Hoffman's series with locking plates excellent outcomes were achieved in $20.8 \%$, good in $27.4 \%$, fair in $45.3 \%$ and poor in $6.6 \% 4$. Complications including malunion, delayed union, non-union and implant failure are not infrequent 22,25 . When using locked plating, non-union rates up to $20 \%$ have been reported 4,10,25,26. Peri-articular fractures add to the complexity of surgical management and significantly worse outcomes are seen with a significantly greater incidence of failed hardware ${ }^{4}$.

\section{Fracture reduction}

Regardless of implant choice, the principles and methods of fracture reduction and mangagment are the same (Table 4). For intra-articular fracture reduction, depending on the fracture pattern, this is typically done through a parapatellar approach, with the patella retracted to visualise the articular surface. Plates can positioned along both medial and lateral sides of the femur in the submuscular plane using these approaches, or a retrograde nail implanted.

For diametaphyseal fracture indirect reduction with minimal soft tissue stripping should occur. In distal femur fractures the shaft is the stable portion. Limb alignment is critical to function ${ }^{27}$. The typical fracture deformity is apex posterior angulation due to the gastrocnemius. This is important as any traction manoeuvres for reduction with the knee extended will increase the posterior angulation of the posterior fragment due to gastrocnemius anchorage. Flexion of the knee over a bolster reduces the influence of the gastrocnemius. Coronal plane alignment is the most difficult factor to control and the most crucial to outcome ${ }^{28}$. Options to facilitate reduction include manual traction, use of the AO femoral distractor or external-fixator (positioned anteriorly to allow lateral access). Over reliance on the implant, either nail or plate, to achieve fracture reduction is a high risk strategy, best employed with a thorough knowledge of the implant in use. The risk of fixation with reduction is considerable. In spiral or oblique fractures, augmentation with a cerclage wire can occur to help maintain fracture reduction. This may require clamp assisted reduction, and if so this should be achieved in a minimally invasive manner if possible.

Determination of adequate reduction can be difficult in comminuted fracture patterns as there is no cortical read. Assessment of rotation and length should occur in all cases pre-op before prepping and draping. This can be done by assessing the contralateral leg with pre-operative fluoroscopy shots saved for comparison intra-operatively. Fluoroscopy shots of the unopened implant on the contralateral leg can help with assessment of fracture reduction for length and also in preoperative planning for screw positioning for locked plate use. Determination of rotation can be done by either clinical or radiographic methods, or a combination of both. Clinically, test internal and external rotation of the contralateral leg and compare when finished. In addition acquire a perfect AP image of the knee and move up to get an AP at the hip to compare the shape of the greater and lesser trochanters. 
$\underline{\text { Retrograde intramedullary nailing }}$

Surgical technique

Position the patient supine on a radiolucent table with fluoroscopy unit set up on the contralateral side. Place a sandbag under the buttock and a radiolucent bolster or bump under the distal thigh for fracture reduction and to facilitate access to the entry point. The approach should be sufficient to allow access to the entry point and visualisation of any intra-articular fracture reduction as appropriate. The entry point of the guide wire is critical for the success of the operation. The correct entry point is in the central aspect of the intercondylar notch, anterior to the ACL and PCL attachments (Figure 5). This is the junction of the anterior portion of the intercondylar notch and the inferior posterior part of the patella-femoral joint at Blumensaat's line. An entry point too medial or lateral will translate or angulate the fracture in the coronal plane. An entry point too posterior will cause an extension deformity, and an entry point too anterior will lead to a flexion deformity.

When advancing the entry wire it should be collinear with the intramedullary axis on both AP and lateral views. If there is difficulty with this, the use of blocking screws have been described in distal third fractures ${ }^{29}$. Reaming should occur, with over-reaming typically by $1.5 \mathrm{~mm}$. Care when reaming is required. If the knee is too flexed reaming of the patella may occur, if too extended, reaming of the tibia may occur. Once the nail is correctly positioned, it should be interlocked distally with screws and/or a blade device. Proximal locking screws should be inserted AP through a mini open approach at the lesser trochanter, both for biomechanical reasons, as well as to avoid the nearby neurovascular structures. Due to the bulk of quadriceps muscle and often subcutaneous tissue, suture the screw to the screw driver or use a screwdriver with adequate capture as a screw can be easily lost in a large thigh. The nail should be positioned several millimetres below the articular surface. Patellofemoral pressure increase if the nail has even $1 \mathrm{~mm}$ of prominence ${ }^{30,31}$.

The stability of the fracture can be assessed under continuous fluoroscopy with valgus and varus stress. If greater stability is needed, stabilisation screws can be inserted in a similar fashion to blocking screws. A screw either side of the nail in the metaphysis may "put the nail in jail" and add to the overall stability of the construct. Prior to leaving theatre, always check the femoral neck for fractures, confirm the fracture reduction and the nail position, and examine the knee.

\section{$\underline{\text { Retrograde nailing of intraarticualar fractures }}$}

If an intra-articular extension is present, intra-medullary nailing may still be appropriate. But anatomical reduction and compression of the fracture should occur first prior to indirect reduction and nail insertion to stabilise the diametaphyseal component. There is insufficient evidence to assess the suitability of retrograde medullary nailing of Type $C$ fractures, although both the Hoskins $^{1}$ and Tornetta III ${ }^{32}$ studies included intra-articular fracture types. A subanalysis compared $\mathrm{C} 1$ and $\mathrm{C} 2$ fractures of the distal femur managed with either retrograde intramedullary nail or angular-stable locking plates ${ }^{33}$. This study 
found 47 type $\mathrm{C} 1$ and $\mathrm{C} 2$ fractures managed with plate and 12 with retrograde nail. Coronal plane deformity, EQ-5D at 6 and 12 months were not different, suggesting that retrograde nailing does remain an option for the intra-articular fracture type.

\section{Intramedullary nailing fractures above total knee arthroplasty}

Periprosthetic supracondylar femoral fractures are increasing in fequency. Treatment with a retrograde intramedullary femoral nail requires the positioning of the nail through the femoral prosthesis in line with the intramedullary canal. An understanding of both the arthroplasty components and the intramedullary nail is essential to ensure the compatibility of implants.

The intercondylar width and the position of the notch on the femoral component in relation to the intramedullary canal need to be identified. Thompson et al. compiled a list of knee replacement prostheses dimensions and their compatibility with a retrograde nails ${ }^{34}$. Only 33 of 82 the femoral components listed allow the passage of a retrograde intramedullary nail, and these were generally posterior cruciate retaining arthroplasties. In addition to the femoral component, the polyethylene liner and the patella must be protected during reaming and nail insertion process. The maximum number of distal locking screws should be utilized as number of screws correlates with non-union and reintervention ${ }^{35}$.

\section{$\underline{\text { Fixed angle plating }}$}

\section{$\underline{\text { Surgical technique }}$}

Patient positioning, table choice and theatre set up are no different to intramedullary nailing, as is direct reduction of the articular components and indirect reduction techniques for the diametaphyseal component. Lateral patient positioning is also possible.

If treating anintra-articular fracture, a lateral parapatellar (or more commonly a Swashbuckler) approach is typically made to visualise the articular surface and achieve an anatomical reduction. If not, a lateral approach with splitting of the ITB is performed. In both approaches the plate is then slid sub-muscularly under vastus lateralis and provisionally fixed. Plate positioning on bone is critical. Screw insertion distally should be parallel to the joint surface on a true AP plane, which can be matched to a Kirschner wire run across the knee. A tendency for the plate to sit too anterior should avoided by checking a lateral x-ray. If the plate is placed too posterior, medialisation of the distal femur articular block may occur resulting in a "golf club deformity". If plate position is adjusted, ensure to recheck the AP x-ray. The plate is then affixed to bone using a whirly bird type device or non-locking screw. Although minimally invasive techniques are recommended, a slightly larger incision should be made proximally to ensure the correct plate position by palpating the bone. Bicortical screws enhance the overall stability of the construct and help prevent implant failure through screws pulling out of the bone. 


\section{Fixed angle plate constructs}

Distal femoral plates have evolved from the angular blade plate, through the dynamic condylar screw on to the LISS system and now the condylar plate system with variable angle locking options. All have the similar principle of angular stability. Traditional fixed angle locking plates permit only a single axis of locking screw insertion. This single plane insertion axis can limit locking screw insertion pathways if arthroplasty components or other implants block this path. Variable angle locking screw insertion offers the advantage of locking screw axis variation ${ }^{36}$. Locked plates have become the implant of choice despite no conclusive evidence showing show the benefit of this system over another ${ }^{37}$.. In a large series only $74.8 \%$ healed after the index procedure and only $91.0 \%$ of fractures finally healed, with implant failure occurring in $9.9 \%{ }^{4}$.

Locked plating is not a panacea, but a technique described for bridging. Simple fractures should be reduced anatomically and fixed with compression techniques as per Perren's hypothesis ${ }^{38}$. Simple transverse diaphyseal fractures are a relative contraindication for locked plating. When achieving plate compression or neutralisation, it is appropriate to use an anatomical plate. But the plate does not need to be locked necessarily to function as a neutralisation plate. This distinction is often lost on surgeons who 'bridge' simple fractures with modern plates hoping this will allow them not to bother with reduction, something they would never try to do with a DCS ${ }^{36}$. This is important as locked plating does not substitute for poor reduction or understanding of fracture management principles. On the other hand, rigid fixation is not indicated with comminuted fractures, in particular osteoporotic fractures, and bridge plating is ideal in this situation ${ }^{39}$.

\section{Bridge plating}

With bridge plating, increased working length is required to enhance interfragmentary micromotion and callus formation ${ }^{40}$, due to working lengths influence on axial stiffness and torsional rigidity ${ }^{41}$. Shorter working lengths with higher stiffness have been found related to nonunions ${ }^{4}$, due to suppressing interfragmentary movement and callus formation ${ }^{10,42}$. Too small a working length leads to a construct that is too stiff often associated with implant failure ${ }^{4}$, as stress is concentrated at the short spanning segment ${ }^{43}$. Correct working length for each fracture type and screw placement remains a matter of debate and controversy ${ }^{44}$, but in general, three to four empty holes at the fracture site is recommended $45.71 \%$ of non-unions in one series had no empty screw holes next to the fracture ${ }^{10}$. The overall construct stiffness is also dependent on plate length ${ }^{46}$, plate material and screw number.

Enhanced working length is achieved with the longest plate possible. In complex fractures plate length at least 2-3 times the length of the fracture has been recommended ${ }^{47}$. Given minimally invasive techniques of insertion, a good argument has to be made to span the femur, given that this will also minimise pull out forces acting on screws. Due to a number of reasons, shorter plate length may be a risk factor for non-union ${ }^{46}$.

A number of other factors impact construct stiffness and callus formation, 
including plate material, screw number, screw density, screw position and screw type. Screw density in bridge plating is recommended with a ratio of 0.4 to 0.5 with three to four screws either side of the fracture ${ }^{4,22,41}$ This again can only be achieved with satisfactory plate length. Distal fixation of the condyles should be performed with 4 to 6 screws and additional interfragmentary juxta-articular fixation utilising lag screws if required ${ }^{4}$.

Another issue with fixed angle plates arises with locking screws and eccentric callus formation. A screw well fixed to the cortex and plate may be too rigid and limit micro-motion on the plate side of the bone causing asymmetric stiffness and callus formation ${ }^{39}$. Concerns such as this as led to the development of far cortical locking screws. Off label techniques have also been developed involving over drilling the near cortex with a $5.0 \mathrm{~mm}$ drill to create a $0.5 \mathrm{~mm}$ halo around a standard $4.0 \mathrm{~mm}$ standard locking screw. This results in increased callus on both medial and lateral sides in the fracture region ${ }^{39}$.

Selection of locking plate material is also controversial. Titanium plates with an elasticity modulus more similar to cortical bone, intuitively seem preferred to stainless steel which is stiffer ${ }^{48}$. Clinically, no difference in non-union rates has been found, however ${ }^{4}$. Higher failure rates have been reported with newer distal femur fixed angle locking plate designs ${ }^{36}$.

\section{Intramedullary nailing versus fixed angle plate fixation}

Both retrograde nailing and locked plating if performed minimally invasively have the advantage of preserving 'biology' in the form of blood supply to the fracture site. The decision of which implant to use is generally based on fracture pattern, the desired fixation required and surgeon preference (Table 5 and Table $6)$.

Retrograde intramedullary nailing has many advantages over fixed angle plate fixation ${ }^{10}$. Intramedullary nails are a load sharing device, located closer to the mechanical axis; allow for dynamisation and technical decision making is simpler due to less operative options in terms of working length, bolt type and location. Intramedullary nails mean that metaphyseal comminution irrelevant. Reaming has the advantage of distributing bone graft and may stimulate blood flow. Biomechanical studies have shown retrograde nailing to be more resistant to axial load and load to failure ${ }^{49}$, and callus formation is increased when compared with locking plates ${ }^{10}$.

Disadvantages include the intra-articular starting point, which may contribute to knee stiffness. If the fixation is complicated by infection, the knee joint may now communicate with the shaft, and in gross contamination their use is contraindicated. However, infection risk after nailing open fractures is low $(1 \%)^{50}$. Care must be taken to avoid damage to the ACL during nail insertion. However, if performed correctly there is no long term evidence to suggest this has an impact on knee function. Other disadvantages include potential positioning of locking bolts through coronal fracture lines and stress risers 
forming through unfilled holes. Stability of a comminuted metaphyseal fracture zone may be inadequate and adequate distal bone stock is required.

Fixed angle plating has the major advantages of more locking screw options and improved distal fixation in osteoporotic bone ${ }^{51}$. This makes their spectrum of use wider. In contrast to a nail, plating can be used with different fixation concepts: bridge plating or interfragmentary compression, with bridge plating favoured in comminuted fractures as local bone and soft tissue trauma is minimized. In simple fractures the application of interfragmentary compression can be considered. Biomechanically locked plates are more resistant to torsion than nails 49 .

Disadvantages include the technically and intellectually challenging nature of plate fixation and construct decision, with strong debate existing regarding appropriate plate length, working length, plate material, the number, relative position and type of screws (cortical, locking, monocortical or bicortical) which need to be inserted.

The optimal management of distal femur fractures remains controversial. Retrospective case series have found no difference between retrograde nail versus locked plating for extra-articular distal femur fractures with regard to implant failure and function 52,53 . One study found blood loss and union were higher with retrograde nail ${ }^{52}$, but a larger study did not ${ }^{53}$. A small prospective cohort study found no differences between the nail and locked plate group for non-union, fixation failure and secondary surgical procedures ${ }^{26}$.

In the largest comparative study, there was a clinically relevant and significant difference in quality-of-life at 6 months in favour of intramedullary nail and weak evidence that this trend continued to one year ${ }^{1}$. There was a significant although very small reduction in angular deformity using a nail. However, there was no evidence that there was a difference in any other outcomes at any time point. These findings are similar to data from a recent (unpublished) 23 centre randomized controlled trial comparing these two fixation methods using standardized validated general and disease specific measures as well as radiographic and clinical outcomes ${ }^{32}$. This study found no difference in surgical time or malalignment in any plane, but valgus deformity $>5$ degree was higher in the plate group compared with the nailing group. There was no difference in weight bearing, range of motion, revision or functional outcomes. Overall functional results trended toward better in the nail than plate group at one year without reaching statistical significance. Level 1 evidence from Cochrane has concluded that there is insufficient evidence to make a comparison between the two surgical methods ${ }^{3}$. There is a requirement for a large, well conducted definitive randomized controlled trial.

Similarly in the periprosthetic fracture cohort, Level 1 evidence has demonstrated no difference with regards to non-union rates or secondary surgical procedures, however retrograde nailing had a higher malunion rate ${ }^{54}$. Recent literature has found despite a greater quantity of screws in the distal 
fragment, failure rate of locked plating is twice that of intramedullary nailing55. No difference in time to weight bearing has been found in other studies ${ }^{56}$.

\section{Acute total knee arthroplasty for fracture}

Primary knee arthroplasty is an uncommonly used treatment for distal femur fractures. Typically, this procedure is reserved for lower demand patients with highly comminuted injuries. In carefully selected patients, it can allow immediate motion and early weight bearing through the injured joint. A large volume of bone and soft tissue may be need to be resected in order to incorporate the fracture segments - and this in turn, may require the use of augments, metaphyseal sleeves and stems, as well as prostheses with high levels of constraint in the sagittal and coronal planes, such as a rotating hinge or tumour type 'mega prosthesis' 57,58 .

\section{$\underline{\text { Conclusion }}$}

Distal femur fractures are a surgical challenge with high complication rates. Knowledge and correct application of the principles of fracture management are required to optomise the chance of successful outcome. The main surgical implants are retrograde intramedullary femoral nails and variable angle locking plates. It remains to be seen whether a clinical and cost-effective difference exist between the two. Answers may be forthcoming in large scale randomized controlled trials ${ }^{59}$.

\section{References}

1. Hoskins W, Sheehy R, Edward ER, Hau RC, Bucknill A, Parsons N, Griffin XL. Nails or plates for fracture of the distal femur? Data from the Victoria Orthopaedic Trauma Outcomes Registry. Bone Joint J. 2016; 98-B(6):84650.

2. Tornetta P, Tiburzi D. Antegrade or retrograde reamed femoral nailing: a prospective randomised trial. J Bone Joint Surg (Br). 2000;82:652-4.

3. Griffin XL, Parson N, Zbaede MM, McArthur J. Interventions for treating fractures of the distal femur in adults. Cochrane Database Syst Rev. 2015 Aug 13;(8):CD010606.

4. Hoffmann MF, Jones CB, Sietsema DL, Tornetta P 3rd, Koenig SJ. Clinical outcomes of locked plating of distal femoral fractures in a retrospective cohort.J Orthop Surg Res. 2013;8:43

5. Kolmert L, Wulff K. Epidemiology and treatment of distal femoral fractures in adults. Acta Orthop Scand 1982;53:957-62. 
6. Arneson TJ, Melton LJ, Lewallen DG, O’Fallon WM. Epidemiology of diaphyseal and distal femoral fractures in Rochester, Minnesota, 19651984. Clin Orthop Relat Res 1988;234:188-94.

7. Martinet O, Cordey J, Harder Y, Maier A, Bühler M, Barraud GE. The epidemiology of fractures of the distal femur. Injury 2000;31:62-3.

8. Papadokostakis G, Papakostidis C, Dimitriou R, Giannoudis PV. The role and efficacy of retrograding nailing for the treatment of diaphyseal and distal femoral fractures: a systematic review of the literature. Injury 2005;36:813-22.

9. Zlowodzki M, Bhandari M, Marek DJ, Cole PA, Kregor PJ. Operative treatment of acute distal femur fractures: systematic review of 2 comparative studies and 45 case series (1989 to 2005). Journal of Orthopaedic Trauma 2006;20(5): 366-71.

10. Henderson CE, Kuhl LL, Fitzpatrick DC, Marsh JL. Locking plates for distal femur fractures: is there a problem with fracture healing?. J Orthop Trauma. 2011;25(Suppl 1): S8-S14.

11. Meek RM, Norwood T, Smith R, Brenkel IJ, Howie CR. The risk of periprosthetic fracture after primary and revision total hip and knee replacement. J Bone Joint Surg (Br). 2011;93(1):96-101.

12. Healy WL, Siliski JM, Incavo SJ (1993) Operative treatment of distal femoral fractures proximal to total knee replacements. J Bone Joint Surg Am 75(1):27-34

13. Schroder HM, Berthelsen A, Hassani G, Hansen EB, Solgaard S. Cementless porous-coated total knee arthroplasty: 10-year results in a consecutive series. J Arthroplasty. $2001 ; 16(5): 559-567$.

14. Rorabeck CH, Taylor JW. Periprosthetic fractures of the femur complicating total knee arthroplasty. Orthop Clin North Am. 1999;30(2):265-277

15. Pandy MG, Sasaki K, Kim S. A three-dimensional musculoskeletal model of the human knee joint. Part 1: theoretical construct. Comput Methods Biomech Biomed Engin. 1998;1:87-108.

16. Rorabeck $\mathrm{CH}$, Taylor JW. Classification of periprosthetic fractures complicating total knee arthroplasty. Orthop Clin North Am. 1999;30:209214.

17. Lewis PL, Rorabeck CH. Periprosthetic fractures. IN: Engh GA, Rorabeck CH (editors). Revision Total Knee Arthroplasty. Williams \& Wilkins. 1997.

18. No authors listed. Advanced trauma life support course: student manual. 8th ed. Chicago: American College of Surgeons; 2008.

19. Chan DB, Jeffcoat DM, Lorich DG, Helfet DL. Nonunions around the knee joint. Int Orthop. 2010;34:271-281.

20. Ricci WM, Loftus T, Cox C, Borrelli J. Locked plates combined with minimally invasive insertion technique for the treatment of periprosthetic supracondylar femur fractures above a total knee arthroplasty. J Orthop Trauma. 2006;20:190-196. 
21. Butt MS, Krikler SJ, Ali MS. Displaced fractures of the distal femur in elderly patients. Operative versus non-operative treatment. J Bone Joint Surg Br. 1996 ;78(1) :110-4.

22. Kubiak EN, Fulkerson E, Strauss E, Egol KA. The evolution of locked plates. J Bone Joint Surg Am. 2006;88(Suppl 4):189-200.

23. Kregor PJ, Stannard J, Zlowodzki M, Cole PA, Alonso J. Distal femoral fracture fixation utilizing the Less Invasive Stabilization System (L.I.S.S.): the technique and early results. Injury. 2001;32(Suppl 3):SC32-SC47.

24. Weight $M$, Collinge $C$. Early results of the less invasive stabilization system for mechanically unstable fractures of the distal femur (AO/OTA types A2, A3, C2, and C3). J Orthop Trauma. 2004;18:503-508.

25. Henderson CE, Lujan TJ, Kuhl LL, Bottlang M, Fitzpatrick DC, Marsh JL. Mid-America Orthopaedic Association Physician in Training Award: healing complications are common after locked plating for distal femur fractures. Clin Orthop Relat Res. 2010;2011(469):1757-1765.

26. Markmiller M, Konrad G, Sudkamp N. Femur-LISS and distal femoral nail for fixation of distal femoral fractures: are there differences in outcome and complications?. Clin Orthop Relat Res. 2004;426:252-257.

27. Gwathmey FW, Jones-Quaidoo SM, Kahler D, Hurwitz S, Cui Q. Distal femoral fractures: current concepts. J Am Acad Orthop Surg. 2010;18:597607.

28. Zehntner MK, Marchesi DG, Burch H, Ganz R. Alignment of supracondylar/intercondylar fractures of the femur after internal fixation by A0/ASIF technique. J Orthop Trauma. 1992;6:318-326.

29. Ostrum RF, Maurer JP. Distal third femur fractures treated with retrograde femoral nailing and blocking screws. J Orthop Trauma. 2009;23(9):681-4.

30. Ostrum RF, Agarwal A, Lakatos R, Poka A. Prospective comparison of retrograde and antegrade femoral intramedullary nailing. J Orthop Trauma. 2000;14(7):496-501.

31. Ricci WM, Bellabarba C, Evanoff B, Herscovici D, DiPasquale T, Sanders R. Retrograde versus antegrade nailing of femoral shaft fractures. J Orthop Trauma. 2001;15(3):161-9.

32. Tornetta III P, Egol KA, Jones CB et al. Locked plating versus retrograde nailing for distal femur fractures: A multicentre randomized trial. Orthopaedic Trauma Association 2013, Phoenix, Arizona.

33. Stokes C, Hoskins W, Sheehy R, Bingham R, Bucknill A, Griffin X. Intraarticular fractures of the distal femur: a role for intramedullary nail? Aaustralian Orthopaedic Association Victorian Branch Annual Scientific Meeting 2016, Lorne, Victoria.

34. Thompson SM, Lindisfarne EA, Bradley N, Solan M. Periprosthetic supracondylar femoral fractures above a total knee replacement: compatibility guide for fixation with a retrograde intramedullary nail. J Arthroplasty. 2014;29(8):1639-41. 
35. Toro-Ibarguen A, Moreno-Beamud JA, Porras-Moreno MÁ, Aroca-Peinado M, León-Baltasar JL, Jorge-Mora AA. The number of locking screws predicts the risk of nonunion and reintervention in periprosthetic total knee arthroplasty fractures treated with a nail. Eur J Orthop Surg Traumatol. 2015;25(4):661-4.

36. Tank JC, Schneider PS, Davis E, Galpin M, Prasarn ML, Choo AM, Munz JW, Achor TS, Kellam JF, Gary JL. Early Mechanical Failures of the Synthes Variable Angle Locking Distal Femur Plate. J Orthop Trauma. 2016;30(1):e7-e11.

37. Canadian Orthopaedic Trauma Society. Are Locking Constructs in Distal Femoral Fractures Always Best? A Prospective Multicenter Randomized Controlled Trial Comparing the Less Invasive Stabilization System With the Minimally Invasive Dynamic Condylar Screw System. J OrthopTrauma. 2016;30(1):e1-e6.

38. Perren SM. Evolution of the internal fixation of long bone fractures. The scientific basis of biological internal fixation: choosing a new balance between stability and biology. J Bone Joint Surg Br. 2002 Nov;84(8):1093110.

39. Linn MS, McAndrew CM, Prusaczyk B, Brimmo O, Ricci WM, Gardner MJ. Dynamic Locked Plating of Distal Femur Fractures. J Orthop Trauma. 2015;29(10):447-50.

40. Märdian S, Schaser KD, Duda GN, Heyland M. Working length of locking plates determines interfragmentary movement in distal femur fractures under physiological loading. Clin Biomech (Bristol, Avon). 2015;30(4):391-6.

41. Stoffel K, Dieter U, Stachowiak G, Gachter A, Kuster MS. Biomechanical testing of the LCP-how can stability in locked internal fixators be controlled?. Injury. 2003;34(Suppl 2):B11-B19.

42. Lujan TJ, Henderson CE, Madey SM, Fitzpatrick DC, Marsh JL, Bottlang M. Locked plating of distal femur fractures leads to inconsistent and asymmetric callus formation. J Orthop Trauma. 2010;24:156-162.

43. Strauss EJ, Schwarzkopf R, Kummer F, Egol KA. The current status of locked plating: the good, the bad, and the ugly. J Orthop Trauma. 2008;22:479-486.

44. Bottlang M, Doornink J, Lujan TJ, Fitzpatrick DC, Marsh JL, Augat P, von Rechenberg B, Lesser M, Madey SM. Effects of construct stiffness on healing of fractures stabilized with locking plates. J Bone Joint Surg Am. 2010;92:12-22.

45. Smith WR, Ziran BH, Anglen JO, Stahel PF. Locking plates: tips and tricks. J Bone Joint Surg Am. 2007;89:2298-2307.

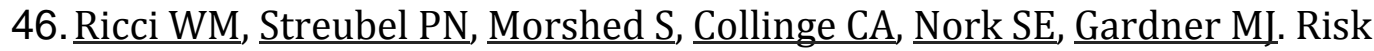
factors for failure of locked plate fixation of distal femur fractures: an analysis of 335 cases. J Orthop Trauma. 2014;28(2):83-9. 
47. Gautier E. Bridge plating. https://www.aofoundation.org/Documents/8_bridgeplating.pdf Accessed 23 July 2016.

48. Beingessner D, Moon E, Barei D, Morshed S. Biomechanical analysis of the less invasive stabilization system for mechanically unstable fractures of the distal femur: comparison of titanium versus stainless steel and bicortical versus unicortical fixation. J Trauma. 2011;71(3):620-4.

49. Başcı O, Karakaşlı A, Kumtepe E, Güran O, Havıtçıŏlu H. Combination of anatomical locking plate and retrograde intramedullary nail in distal femoral fractures: comparison of mechanical stability. Eklem Hastalik Cerrahisi. 2015;26(1):21-6.

50. O'Toole RV, Riche K, Cannada LK, Hennessy M, Sciadini MF, Shi LL, Woodford M, Harris MB. Analysis of postoperative knee sepsis after retrograde nail insertion of open femoral shaft fractures. J Orthop Trauma. 2010;24(11):677-82.

51. Zlowodzki M, Williamson S, Cole PA, Zardiackas LD, Kregor PJ: Biomechanical evaluation of the less invasive stabilization system, angled blade plate, and retrograde intramedullary nail for the internal fixation of distal femur fractures. J Orthop Trauma. 2004;18:494-502.

52. Gao K, Gao W, Huang J, Li H, Li F, Tao J, Wang Q. Retrograde nailing versus locked plating of extra-articular distal femoral fractures: comparison of 36 cases. Med Princ Pract. 2013;22(2):161-6.

53. Hierholzer C, von Rüden C, Pötzel T, Woltmann A, Bühren V. Outcome analysis of retrograde nailing and less invasive stabilization system in distal femoral fractures: A retrospective analysis. Indian J Orthop. 2011;45(3):243-50.

54. Ristevski B, Nauth A, Williams DS, Hall JA, Whelan DB, Bhandari M, Schemitsch EH. Systematic review of the treatment of periprosthetic distal femur fractures. J Orthop Trauma. 2014;28(5):307-12.

55. Meneghini RM, Keyes BJ, Reddy KK, Maar DC. Modern retrograde intramedullary nails versus periarticular locked plates for supracondylar femur fractures after total knee arthroplasty. J Arthroplasty. 2014;29(7):1478-81.

56. Horneff JG 3rd, Scolaro JA, Jafari SM, Mirza A, Parvizi J, Mehta S. Intramedullary nailing versus locked plate for treating supracondylar periprosthetic femur fractures. Orthopedics. 2013;36(5):e561-6.

57. Nau T, Pflegerl E, Erhart J, Vecsei V. Primary total knee arthroplasty for periarticular fractures. J Arthroplasty. 2003;18:968-971.

58. Appleton P, Moran M, Houshian S, Robinson CM. Distal femoral fractures treated by hinged total knee replacement in elderly patients. J Bone Joint Surg Br. 2006;88:1065-1070.

59. Trial of acute femoral fracture fixation. ISRCTN92089567. 


\section{Figures}

Figure 1. Anatomy of the distal femur

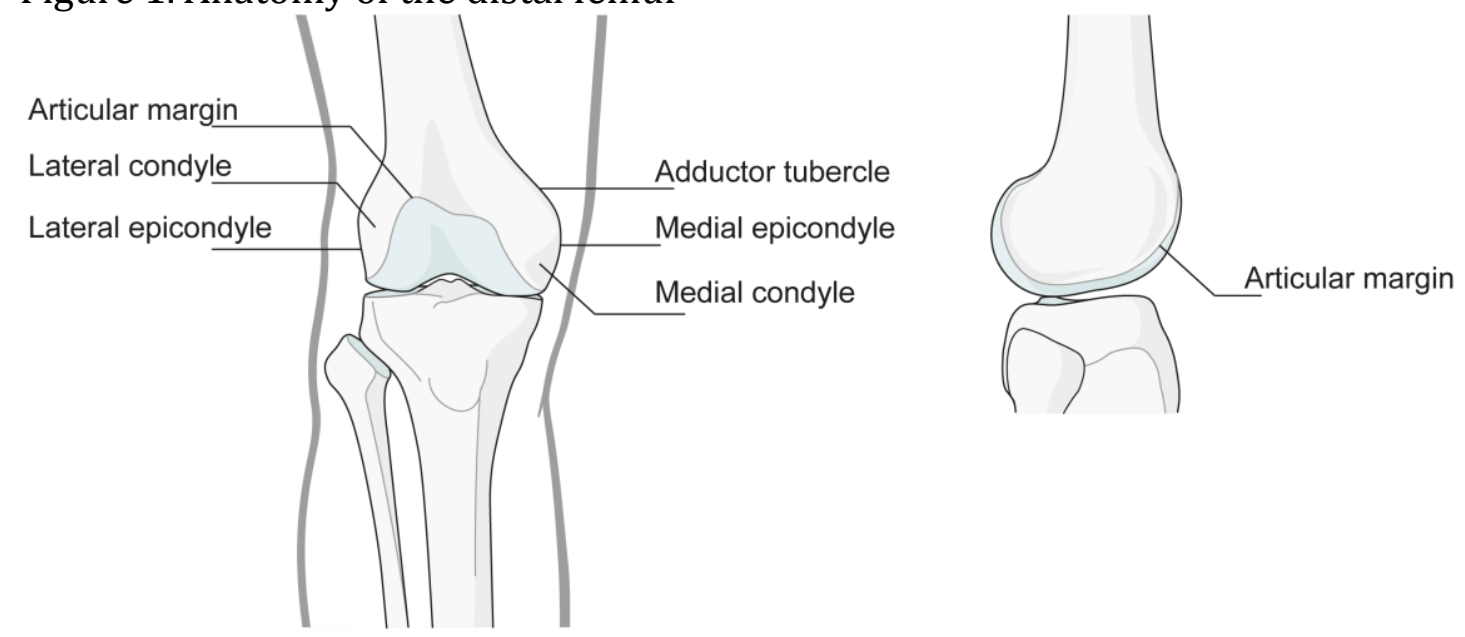


Figure 2. Trapezoidal shape of the distal femur

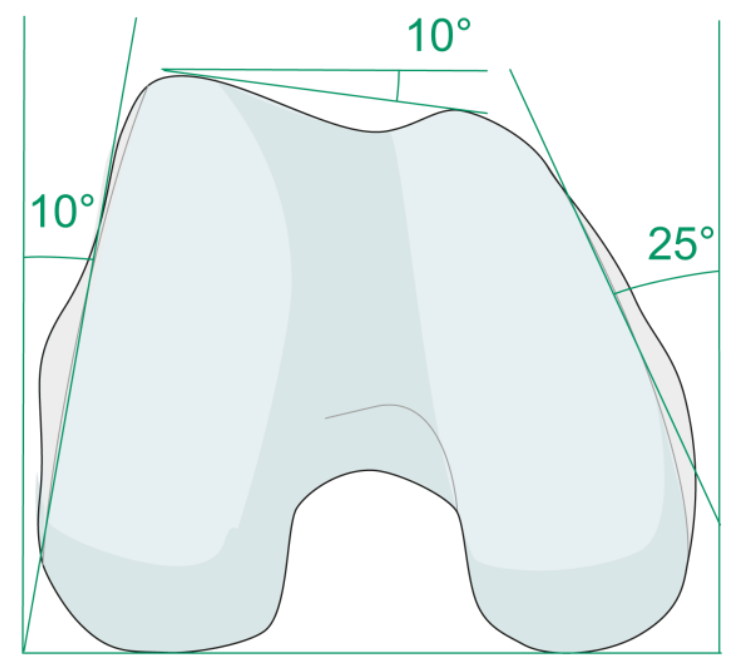


Figure 3. A0/OTA Classification of distal femur fractures

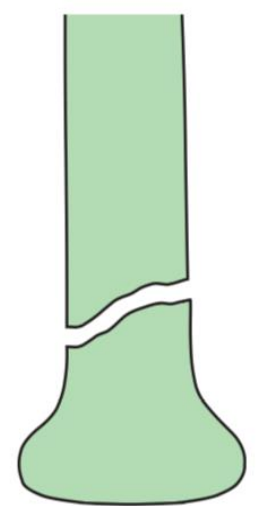

A

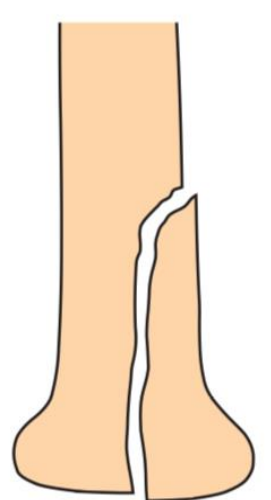

B

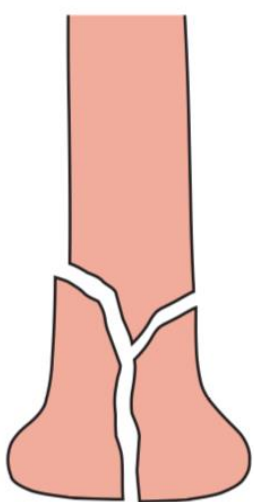

C 
Figure 4. A0/OTA Classification of C type distal femur fractures

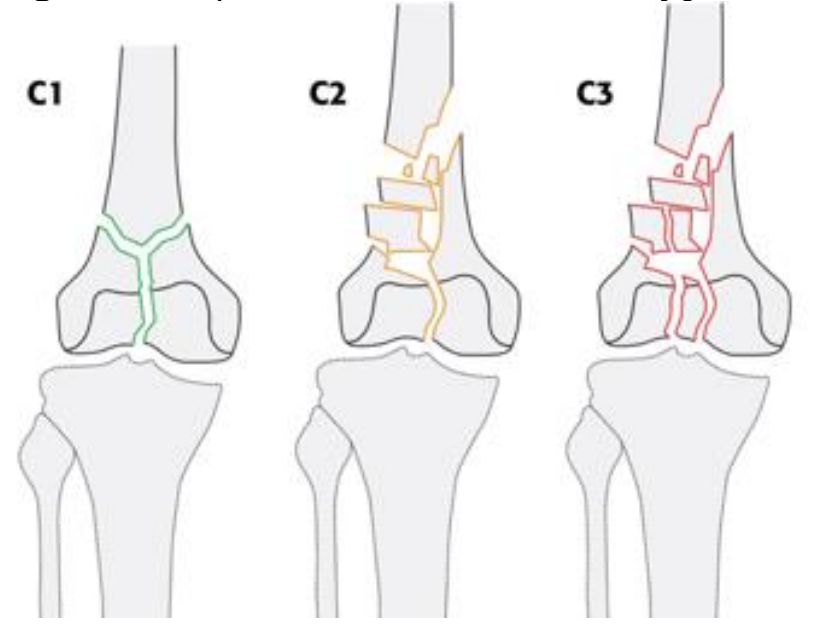


Figure 5. Correct entry point for retrograde femoral nailing

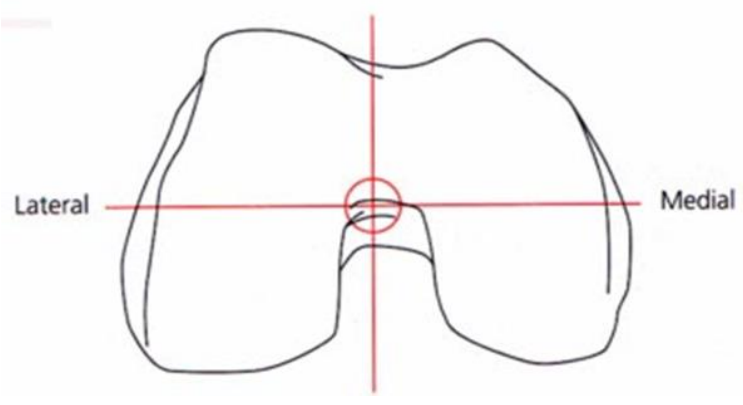




\section{Tables}

Table 1. AO/OTA Classification of distal femur fractures

\begin{tabular}{|l|l|l|}
\hline $\begin{array}{l}\text { AO/OTA } \\
\text { Classification }\end{array}$ & Description & $\begin{array}{l}\text { Frequency (Hoffman } \\
\text { et al. 2013) }\end{array}$ \\
\hline A & Extra-articular fractures & $39.6 \%$ \\
\hline B & $\begin{array}{l}\text { Partial articualr fractures with an } \\
\text { intact portion of the joint }\end{array}$ & $3.6 \%$ \\
\hline C & $\begin{array}{l}\text { Extra-articular fractures with } \\
\text { intraarticular extension }\end{array}$ & $56.7 \%$ \\
\hline
\end{tabular}


Table 2. Lewis and Rorabeck Classification of periprosthetic fractures

\begin{tabular}{|l|l|}
\hline $\begin{array}{l}\text { Lewis and Rorabeck } \\
\text { Classification }\end{array}$ & Description \\
\hline I & Nondisplaced fracture with an intact component \\
\hline II & Displaced fracture with an intact component \\
\hline III & $\begin{array}{l}\text { Displaced fracture with a loose or failing } \\
\text { compononent }\end{array}$ \\
\hline
\end{tabular}


Table 3. Surgical decision making for implant choice using fracture classification

\begin{tabular}{|l|l|}
\hline $\begin{array}{l}\text { AO/OTA } \\
\text { Classification }\end{array}$ & $\begin{array}{l}\text { Options are fixed angle plate or retrograde intramedullary } \\
\text { nailing if there is enough room for locking screws - } \\
\text { generally considered possible if the metaphyseal injury is } \\
>4 \mathrm{~cm} \text { from the notch }\end{array}$ \\
\hline A & $\begin{array}{l}\text { These are shear fractures and lag screws, buttress plates } \\
\text { and antiglide plates can be used to stabilise the rest of the } \\
\text { joint to the shaft. }\end{array}$ \\
\hline C & $\begin{array}{l}\text { The complexity of the joint fracture determines the options } \\
\text { for stabilisation. In a simple joint injury with large } \\
\text { condylar fragments (Type C1 and C2), lag screws can be } \\
\text { used to stabilise the joint with a nail or plate used for the } \\
\text { metaphyseal component. If complex intra-articular } \\
\text { comminution exists (Type C3), retrograde nailing is } \\
\text { contra-indicated as it will not accept a nail due to hoop } \\
\text { stresses and poor fixation of the locking screws. }\end{array}$ \\
\hline
\end{tabular}


Table 4. Principles of management of distal femur fractures

Respect the soft tissues and preserve biology.

Direct anatomic reduction of the articular component with absolute stability and interfragmentary compression.

Functional indirect reduction of the diametaphyseal component to restore length and alignment (mechanical axis), both angular and rotational with relative stability.

Provide adequate fixation for early mobility.

Treat each component separately. 
Table 5. Indications for retrograde intramedullary nail instead of locked plating Ipsilateral neck and shaft fractures Floating knee

Obese patients

Periprosthetic fractures about a total knee arthroplasty with a cruciate retaining implant, with sufficient room for nail passage 
Table 6. Indications for locked plating over retrograde intramedullary nail Complex intra-articular fractures (Type C3).

Fractures beneath a total hip arthroplasty.

Distal 33-A type fractures.

Excess anterior femoral bow.

Skeletally immature patients with comminuted fractures.

Narrow femoral canal.

Significant soft tissue injury at nail insertion point. 